\title{
Ureteral Triplication Associated With Upper Pole Ureteropelvic Junction Stenosis
}

\author{
Nebil Akdogan ${ }^{\mathrm{a}}$, Fatih Gokalp ${ }^{\mathrm{b}, \mathrm{c}}$, Volkan Izol ${ }^{\mathrm{a}}$, Nihat Satar ${ }^{\mathrm{a}}$
}

\begin{abstract}
Triplication of ureter (TU) is a rare but important disease occurring in children. TU occurs with the early division of the ureteric bud or with three buds arising from mesonephric duct. It is commonly associated with other urological anomalies such as contralateral ureteric duplication, ureteral ectopia and renal dysplasia. Our case is a 3-yearold girl who presented with right triplex ureters and ureteropelvic junction (UPJ) obstruction of the upper pole. Diagnostic tools used in our case study were ultrasound (US), retrograde pyelography and CT urography for imaging. CT urography is a useful diagnostic tool for pediatric patients because it gives more information about anatomical details.
\end{abstract}

Keywords: Ureter; Number of anomalies; Renal surgery; Endourology

\section{Introduction}

Ureteral anomalies are an important but seldom occurring in childhood. Ureteral duplication is the most common form of anomaly. It may be associated with urinary symptoms due to ureterocele or reflux while following the Meyer-Weigert law (the laterocranial ostium corresponds to the caudal renal pelvis and the mediocaudal ostium to the cranial renal pelvis) but is also compatible with a normally functioning renal system when both ureters enter orthotopically. Triplication of the ureter (TU) is an extremely rare anomaly and does not always follow this law. It was first described by Wrany in 1870 [1] and was classified into four groups by Smith in the 1940s [2]. Type I, the most common form, occurs when all three ureters drain into different orifices [3]. Triplication can occur in conjunction with other urological anomalies such as ureteral ectopia and renal dysplasia. Our case study is a 3-year-old child who pre-

Manuscript submitted April 15, 2018, accepted May 23, 2018

aUniversity of Cukurova, Faculty of Medicine, Department of Urology, Adana, Turkey

${ }^{\mathrm{b}}$ Cihanbeyli Government Hospital, Urology Clinic, Konya, Turkey

${ }^{c}$ Corresponding Author: F. Gokalp, Cihanbeyli Government Hospital, Urology

Clinic, Konya, Turkey. Email: fatihgokalp85@gmail.com

doi: https://doi.org/10.14740/jmc3060w sented with ureteric triplication and upper pole ureteropelvic junction (UPJ) obstruction.

\section{Case Report}

A 3-year-old girl with dysuria and fever was referred to the urology clinic with recurrent urinary infections. Physical examination was ordinary and the patient was fit and also had no relevant medical history before. Ultrasound showed right hydropyonephrosis due to UPJ obstruction and a possible duplex system and regular left system. We inserted a percutaneous nephrostomy to drain the collecting system. The patient was received broad-spectrum antibiotics. CT urography showed right triplication of the ureter and the upper moiety had sequelae of chronic obstruction: parenchymal thinning and right hydronephrosis due to UPJ obstruction. Radiological renal scans showed reduced functioning right upper pole and renal scarring because of obstruction.

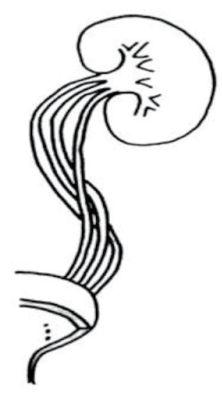

Type I

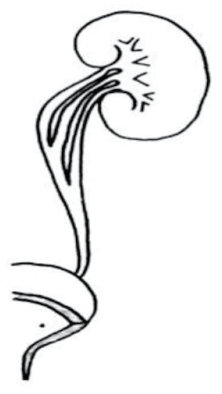

Type III

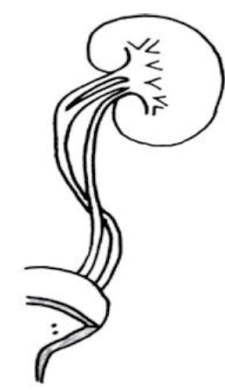

Type II

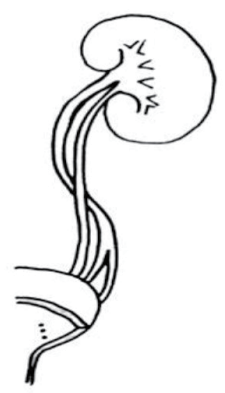

Type IV
Figure 1. Smith's classification of ureteral triplication. 


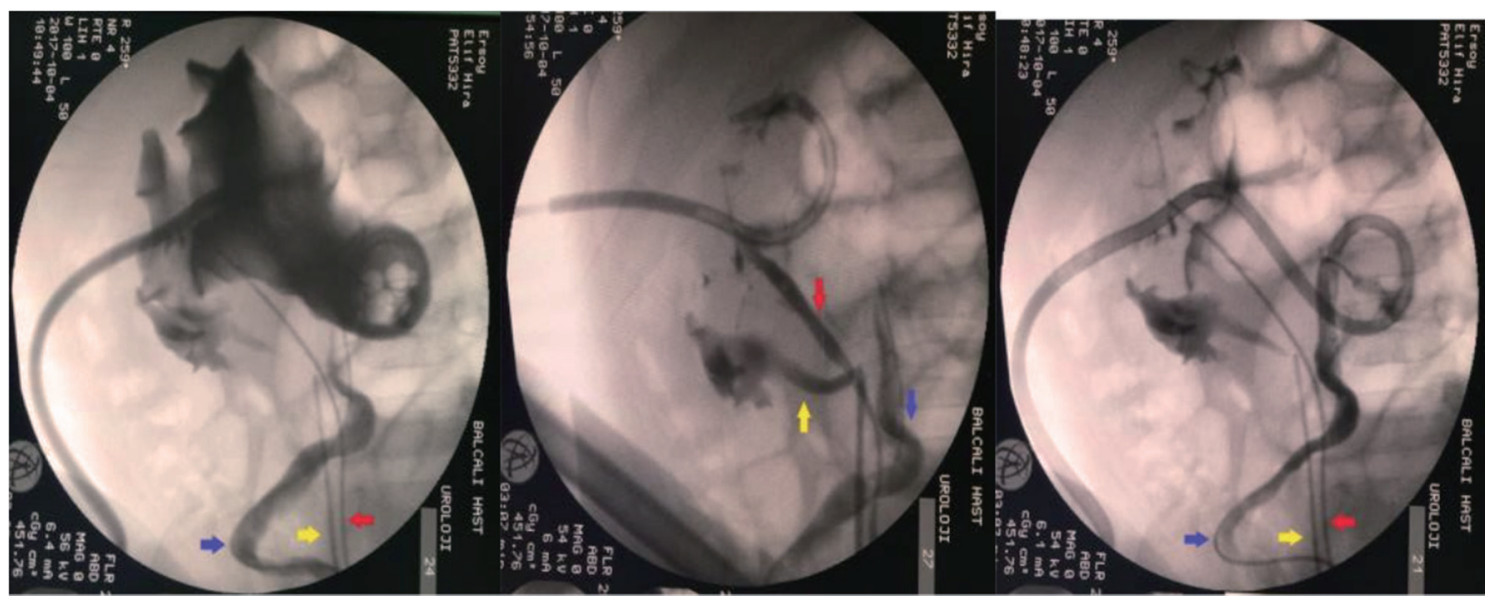

Figure 2. Retrograde pyelogram demonstrates triplicate of ureters and ureteropelvic junction obstruction of upper pole.

The patient underwent cystoscopy and retrograde pyelography for the confirmed right UPJ obstruction. The cystoscopy revealed two right orifices, one of which opened ectopically at the bladder neck while the other consisted of an incomplete separation of two ureters opening into one orifice in the orthotopic position and one on the left. This configuration matched the Type II Smith classification as seen in Figure 1. Retrograde pyelography showed triple ureters visualized on screen. Figure 2 shows right ureteral triplication and the obstructed ureteropelvic junction.

We performed open pyeloplasty for UPJ obstruction of the upper pole. The ectopic ureter was re-implanted according to the Leadbetter-Politano technique during the same operation. The operating time was $180 \mathrm{~min}$. The postoperative period was uneventful, and the girl was discharged after 6 days. The patient had complained recurrent urinary tract infection (UTI) after 4 months. The control images showed right hydronephrosis of upper pole and non-functioning upper pole on renal scan. The patient underwent laparoscopic heminephroureterctomy. There were no perioperative and postoperative complications. The patient discharged after 4 days when symptoms relieved and the patient was asymptomatic at the 6-month follow-up.

\section{Discussion}

$\mathrm{TU}$ is a very rare congenital anomaly of the urinary tract. TU is assumed to occur either as a result of early division of the ureteric bud or when three buds arise from the mesonephric duct at around the fifth week of gestation. TU was classified into four groups by Smith in 1946 [2] and more than 100 known cases have been reported in the literature. Type I is three separate ureters opening with different attachments to the bladder and accounts for $35 \%$ of triplications. Type II is incomplete separation with two ureteral orifices (21\%). Type III is a trifid ureter with all three joining and draining into one ureteral orifice (31\%). Type IV is two ureters one of which is an inverted$\mathrm{Y}$ bifurcation resulting in three orifices $(9 \%)$.

$\mathrm{TU}$ is seen frequently associated with other urological anomalies such as contralateral ureteric duplication, ureteral ectopia, vesicoureteral reflux (VUR) and renal anomalies. The most common associated malformation is contralateral ureter duplication $(37 \%)$ followed by ureteral ectopia $(28 \%)$, renal dysplasia (8\%) and reflux [4-7]. In additionally, number of ureteral anomalies rarely associated with UPJ obstruction and has been reported only a few cases. In our case, TU was associated with UPJ obstruction of upper pole $[6,8,9]$. TU is commonly symptomatic and presents with urinary tract infections, urinary incontinence, abdominal or flank pain. Only $8 \%$ of cases remain asymptomatic. TU is rarely associated with recurrent acute epididymitis [10].

Several assessments are needed before surgery. Diagnostic tools include ultrasonography, CT urography, magnetic resonance urography, renal scan and retrograde pyelography. Ultrasound is a common tool for diagnosing urinary tract obstruction, stones or infection because it is a procedure that is both inexpensive and easy to perform, which is why it is used extensively. However, it is not always able to determine the number of collecting systems. Intravenous pyelography may be useful in defining the abnormal anatomy and determining the number of ureters [11]. CT urography gives more information about the collecting systems and renal parenchyma, but the procedure involves contrast dye and radiation, thus limiting its practicability in children. Magnetic resonance urography offers a higher resolution compared to ultrasonography and provides more anatomic details about the kidney than a MAG-3 renal scan in addition to morphological information. Furthermore, it does not involve the use of ionizing radiation [12-14]. Magnetic resonance urography has been recently described as an additional diagnostic tool for pediatric urological cases $[12,15]$.

TU is typically treated using surgery, depending on the clinical presentation. The treatment of TU is most often indicated in cases of obstruction, ureteral ectopy, vesicoureteral reflux and recurrent infections when there is a risk of renal damage. Early operative therapies such as ureteral re-implantation and subureteral injection for the ureteral ectopia or vesicoureteral reflux can prevent loss of renal function. Heminephrectomy with the removal of the abnormal ureters has 
been shown to be effective for persistent UTIs due to nonfunctioning moiety.

\section{Conclusions}

Ureteral triplication is a rare but important disease associated with renal anomalies due to causing loss of renal function. UPJ obstruction could be rarely associated with number of anomalies. CT urography is an important imaging modality to diagnose number of anomalies and for using preoperative planning. But it has still limitations for using childhood.

\section{Conflict of Interest}

None.

\section{References}

1. Wrany A, Oester JB. Peadiatrik 1: 108.1870.

2. Smith I. Triplicate ureter. Br J Surg. 1946;34(134):182185.

3. Kohri K, Nagai N, Kaneko S, Iguchi M, Minami K, Kadowaki T, Akiyama T, et al. Bilateral trifid ureters associated with fused kidney, ureterovesical stenosis, left cryptorchidism and angioma of the bladder. J Urol. 1978;120(2):249-250.

4. Bloom RA, Crooks KK, Wise HA, 2nd. Complete ureteral triplication with ectopia. Urology. 1985;25(2):176-178.

5. Ander H, Ziylan O, Cayan S, Kadioglu TC, Besisik A. A case of ureteral triplication (type 1) associated with vesicoureteral reflux in a solitary kidney. Int Urol Nephrol.
1997;29(5):537-540.

6. Sivrikaya A, Cay A, Imamoglu M, Sarihan H. A case of ureteral triplication associated with ureteropelvic junction obstruction. Int Urol Nephrol. 2007;39(3):755-757.

7. Soyklemez H, Koplay M, Altunoduk B, et al. Ureteral triplication and contralateral duplication with vesicuoureteral reflex. Balkan Med J. 2011;28:469-470.

8. Horst M, Smith GH. Pelvi-ureteric junction obstruction in duplex kidneys. BJU Int. 2008;101(12):1580-1584.

9. Kokabi N, Price N, Smith GH, Gibbons PJ, Holland AJ. Ureteral triplication: a rare anomaly with a variety of presentations. J Pediatr Urol. 2011;7(4):484-487.

10. Ali SN, Ali AN, Ahmad N, Ali MN. Ureteral triplication and contralateral duplication with vesicoureteral reflux. J Ayub Med Coll Abbottabad. 2014;26(2):258-260.

11. Ochoa Urdangarain O, Hermida Perez JA, Montes de Oca JO, Miranda Rosales F, Rivero Garcia C. [Complete triple ureter. Case report]. Arch Esp Urol. 2006;59(3):284-287.

12. Grattan-Smith JD, Little SB, Jones RA. MR urography in children: how we do it. Pediatr Radiol. 2008;38(Suppl 1):3-17.

13. Boss A, Schaefer JF, Martirosian P, Hacker HW, Darge K, Claussen CD, Kuper K, et al. Contrast-enhanced dynamic MR nephrography using the TurboFLASH navigator-gating technique in children. Eur Radiol. 2006;16(7):15091518.

14. Boss A, Schaefer JF, Martirosian P, Obermayr F, Fuchs J, Claussen CD, Schick F, et al. [Dynamic magnetic resonance nephrography and urography of uropathies in children]. Rofo. 2007;179(8):832-840.

15. Lipson JA, Coakley FV, Baskin LS, Yeh BM. Subtle renal duplication as an unrecognized cause of childhood incontinence: diagnosis by magnetic resonance urography. J Pediatr Urol. 2008;4(5):398-400. 